\title{
Antioxidant properties of natural compounds used in popular medicine for gastric ulcers
}

M.G. Repetto and S.F. Llesuy
Laboratorio de Estrés O xidativo en Patologías Humanas, Cátedra de Q uímica General e Inorgánica, Departamento de Química Analítica y Fisicoquímica, Facultad de Farmacia y Bioquímica, Universidad de Buenos Aires and CO NICET, Buenos Aires, Argentina

\section{Correspondence \\ M.G. Repetto \\ Laboratorio de Estrés 0 xidativo \\ en Patologías Humanas \\ Cátedra de Q uímica General e \\ Inorgánica \\ Departamento de Q uímica Analítica \\ y Fisicoquímica \\ Facultad de Farmacia y Bioquímica \\ Universidad de Buenos Aires \\ Buenos Aires \\ Argentina \\ Fax: + 54-11-4431-7477 \\ E-mail: mrepetto@ huemul.ffyb.uba.ar \\ Presented at the XVI Annual Meeting of the Federação de Sociedades de Biologia Experimental, Caxambu, MG, Brazil, August 29 - September 1, 2001. \\ Research supported by U niversidad de Buenos Aires and Consejo $\mathrm{N}$ acional de Investigaciones Científicas y Técnicas (CO NICET).}

Received August 24, 2001 Accepted March 12, 2002

\begin{abstract}
There is evidence concerning the participation of reactive oxygen species in the etiology and physiopathology of human diseases, such as neurodegenerative disorders, inflammation, viral infections, autoimmune pathologies, and digestive system disorders such as gastrointestinal inflammation and gastric ulcer. The role of these reactive oxygen species in several diseases and the potential antioxidant protective effect of natural compounds on affected tissues are topics of high current interest. To consider a natural compound or a drug as an antioxidant substance it is necessary to investigate its antioxidant properties in vitro and then to evaluate its antioxidant functions in biological systems. In this review article, we shall consider the role of natural antioxidants derived from popular plants to reduce or prevent the oxidative stress in gastric ulcer induced by ethanol.
\end{abstract}

Key words - Antioxidant

- Free radicals

- Natural antioxidants

- Gastric ulcers

- Artemisia douglasiana Besser

- Dehydroleucodine

\section{Introduction}

In Argentina the Artemisia douglasiana Besser plant, popularly known as "matico", is used in popular medicine as a cytoprotective agent for gastric ulcers, for external treatment of skin injuries and for dermal ulcers. The active principle of this plant is dehydroleucodine $(\mathrm{DhL})$, a sesquiterpene lactone of the guaianolide type. $\mathrm{DhL}$ increases gastric glycoprotein synthesis (1), as demonstrated by histological studies of the gastric and duodenal mucosa (2), and prevents lesions of the gastric mucosa induced by ethanol and other necrotizing agents (3). The $A$. douglasiana Besser extract and DhL prevent the absolute ethanol-induced gastric injury (4). The mechanism of the protective action of DhL is unknown although it seems to be related to endogenous prostaglandin.

\section{Oxidative stress in gastric mucosa}

The etiology of gastroduodenal ulcers is influenced by various aggressive and defensive factors such as acid-pepsin secretion, parietal cell, mucosal barrier, mucus secretion, blood flow, cellular regeneration, and endogenous protective agents (prostaglandins and epidermic growth factors).

The reactive oxygen species generated by the metabolism of arachidonic acid, platelets, macrophages, and smooth muscle cells may contribute to gastric mucosal damage. Therefore, by scavenging free radicals, the reactive oxygen metabolites might be useful 
by protecting the gastric mucosa from oxidative damage or by accelerating healing of gastric ulcers (5).

Several mucosal defense mechanisms protect the stomach and duodenum from noxious agents (6).

Antioxidants act as radical scavengers, inhibit lipid peroxidation and other free radical-mediated processes, and therefore they protect the human body from several diseases attributed to the reactions of radicals. Numerous substances have been suggested to act as antioxidants. Various phenolic antioxidants such as flavonoids, tannins, coumarins, xanthenes and, more recently, procyanidins have been shown to scavenge radicals in a dose-dependent manner and therefore are viewed as promising therapeutic drugs for free radical pathologies (7).

Herbalists and indigenous healers have used botanical medicines traditionally worldwide for the prevention and treatment of different pathologies. Clinical research has confirmed the efficacy of several plants for the treatment of gastroduodenal disease, while basic scientific research has uncovered the mechanisms by which some plants exert their therapeutic effects $(8,9)$.

\section{Gastric mucus}

Gastric mucus is an important protective factor for the gastric mucosa and consists of a viscous, elastic, adherent and transparent gel formed by $95 \%$ water and $5 \%$ glycoproteins that covers the entire gastrointestinal mucosa. Moreover, mucus is capable of acting as an antioxidant, and thus can reduce mucosal damage mediated by oxygen free radicals. The protective properties of the mucus barrier depend not only on the gel structure but also on the amount or thickness of the layer covering the mucosal surface (10).

A decrease in gastric mucus renders the mucosa susceptible to injuries induced by acid, aspirin or cold restraint stress (11). If some oxygen radicals are generated in sur- face epithelium containing mucus, intracellular mucus could scavenge them. Even when cells containing mucus are damaged by extracellular oxygen radicals, intracellular mucus may be released into the gastric tissue and prevent additional damage by scavenging them (12).

\section{Endogenous gastroprotective molecules}

The defense mechanism of the gastrointestinal mucosa against aggressive factors mainly consists of functional, humoral and neuronal factors. Alkaline mucus secretion, mucosal microcirculation, and motility act as functional factors, while prostaglandin and nitric oxide act as humoral factors. All of the above factors are known to contribute to mucosal protection. Gastric mucosal glycoprotein plays one of the most important roles as a defensive factor of the gastric mucosa (13).

In recent years, heat shock proteins, including HSP70, have been implicated as additional factors utilized by the defense mechanisms of the gastrointestinal mucosa at the intracellular level (14), most probably through key enzymes related to cytoprotection (15). Other evidence of a response is that HSP60 may play a role in triggering the inflammatory process in the gastric mucosa (16).

The HSP70 family functions as a molecular chaperone, reduces stress-induced denaturation and aggregation of intracellular proteins, and exerts its cytoprotective action by protecting mitochondria and by interfering with the stress-induced apoptotic programmer. Nontoxic HSP70 inducers may be of potential benefit for the prevention and treatment of stress ulcer $(17,18)$.

Ethanol exposure appears to induce oxidative stress, which may account for the decreased nitric oxide release, because nitric oxide may be shunted toward scavenging free radicals. Increased endothelial nitric oxide synthase protein expression may be a 
response to the increased demand for nitric oxide (19).

Kato et al. (20), in a study examining alterations of gastric ulcerogenic and healing responses in adjuvant-induced arthritic rats, reported that the ulcerogenic response to ethanol was prevented by increased production of nitric oxide and inducible nitric oxide synthase and was also partially related to elevated production of prostaglandin and cyclooxygenase- 2 .

\section{Oxidative stress in the stomach and acute ethanol toxicity}

Mucosal damage can be easily produced by the generation of exogenous and endogenous active oxygen and free radicals (21).

The process of lipid peroxidation is mediated by the interaction of hydroxyl radicals with the cell membrane; subsequently producing lipid-derived free radicals such as conjugated dienes and lipid hydroperoxides. These radicals are known to be extremely reactive products that cause oxidative damage. Ethanol increases superoxide anion and hydroxyl radical production and lipid peroxidation in the gastric mucosa (22).

Ethanol-induced gastric damage may be due to a direct action of the gastric epithelium causing lipid peroxidation, but this damage can be prevented by prostaglandin administration. Several studies have shown antioxidant activity of flavonoids and another natural compounds (23).

Ethanol treatment induces intracellular oxidative stress and produces mitochondrial permeability transition and mitochondrial depolarization, which precede cell death in gastric mucosal cells. Intracellular antioxidants such as glutathione may have a significant protective action against ethanol in gastric mucosal cells (24). Ethanol is involved in the formation of free radicals generated extracellularly and/or intracellularly. Because intragastric administration of superoxide dismutase was able to protect the gastric mucosa against the damaging effect of ethanol, this would suggest the involvement of superoxide free radicals in the pathogenesis of ethanol-induced gastric mucosal damage $(25,26)$ (Figure 1).

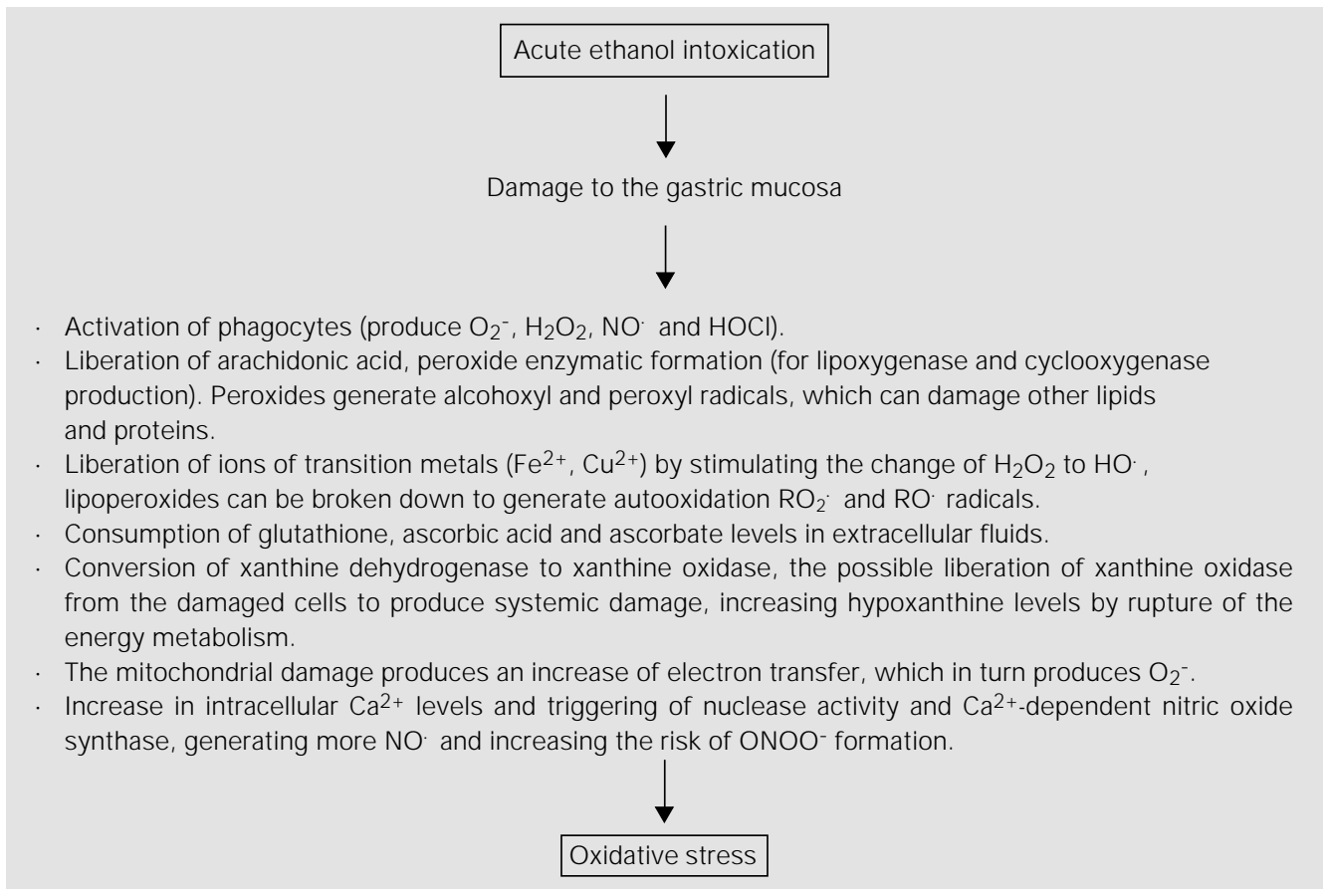

Figure 1. Oxidative stress and physiological consequences of acute ethanol intoxication in gastric mucosa. 


\section{Gastric ulcers and erosions caused by ethanol}

The acute administration of absolute ethanol to rats produces gastric mucosal lesions and erosions similar to those occurring in gastric ulcer (3). The extent of erosion of the glandular area of the stomach mucosa in rats treated with absolute ethanol was scored according to the system designed by MarazziUberti and Turba (27) as follows: 0, no erosions; 1, 1-3 small erosions (4 $\mathrm{mm}$ in diameter or smaller); 2 , more than 3 small erosions or one large erosion; 3 , one large erosion and more than 3 small erosions; 4, 3 4 large erosions; 5 , any very large erosion or ulcer perforation. When the stomach of the rats was treated with ethanol, the extent of erosion of the gastric mucosa corresponded to a factor of 4.5 (large erosions and ulcerative perforations) (28).

Another known cause of erosive lesions in the gastroduodenal mucosa is the hemorrhagic injury produced by exogenous compounds, mainly acetylsalicylic acid, non-steroid anti-inflammatory drugs and high levels of ethanol. These lesions are produced because these compounds can affect the protective defense mechanisms of the mucus.

The tissue damage to the gastrointestinal mucosa induced by acute and chronic ethanol toxicity may be associated with the generation of toxic reactive species which produces an unbalanced oxidant/antioxidant cellular process. The relation between the gastric mucosal damage and antioxidative protection has not been studied.

Previous studies on the gastric mucosa have evaluated lipid peroxidation by measuring the levels of thiobarbituric acid reactive species and chemiluminescence.

Acute ethanol treatment induces oxidative stress, DNA damage, increased xanthine oxidase activity and malondialdehyde levels, and decreased total GSH content in gastric mucosal cells (29).

Intracellular antioxidants such as gluta- thione and $\alpha$-tocopherol protect the gastric mucosa from ethanol-induced oxidative stress. When the antioxidant defense system is insufficient free radicals are accumulated causing injury to the cell membrane, oxidative damage and cell death if the insult continues.

Another hypothesis proposed to explain the ethanol-induced oxidative damage to the gastric mucosa is the constrictive effect on veins and arteries of the gastric mucosa, producing congestion, inflammation and tissue injury. The ethanol-induced lesions depend on the dose of ethanol and can be prevented by $\mathrm{PGE}_{2}$, which inhibits gastric motility and increases the mucus secretion (30). Gastric mucus protects the stomach epithelium from reactive oxygen species in vitro (21). If gastric mucus is decreased, the mucosa is more susceptible to oxidative damage (3).

Synthetic antioxidants are used extensively as food additives and, accordingly, are consumed in appreciable quantities. Evidence has been accumulating that toxicity problems have arisen with these agents and there has been increasing interest in the development of natural antioxidants.

\section{Herbal medicines and natural compounds}

The origins of the therapeutic use of herbal medicine can be traced back to China about 5000 years ago. The extracts of several plants have been used as therapeutic agents.

Spices and herbs are recognized as sources of natural antioxidants that can protect from oxidative stress and thus play an important role in the chemoprevention of diseases resulting from lipid peroxidation (31). The medicinal properties of folk plants are mainly attributed to the presence of flavonoids, but they may be also influenced by other organic and inorganic compounds such as coumarins, phenolic acids and antioxidant micronutrients, e.g., $\mathrm{Cu}, \mathrm{Mn}, \mathrm{Zn}$ (7). 
Flavonoids and other polyphenols belong to the recently popular phytochemicals, chemicals derived from plant material with potentially beneficial effects on human health. The compounds are known as secondary plant metabolites, a designation indicating that most of these substances have been regarded as nonessential and therefore secondary in function. Yet over the years they have been found to be an important part of the human diet and are considered to be active principles in some medicinal plants. The antioxidant activity of flavonoids is efficient in trapping superoxide anion $\left(\mathrm{O}_{2}{ }^{-}\right)$, hydroxyl $\left(\mathrm{OH}^{*}\right)$, peroxyl $\left(\mathrm{ROO}^{\bullet}\right)$ and alcohoxyl (RO•) radicals.

The anti-ulcerogenic pharmacological effect of these plants is related to their flavonoid content. Flavonoids are diphenylpropanes that commonly occur in plants (more than 4000 flavonoids have been found) and are frequent components of the human diet. The immediate family members of flavonoids include flavones, isoflavones and 2,3dihydroderivatives of flavone, namely flavanones, which are interconvertible with the isomeric chalcones. The flavonoids that contain multiple $\mathrm{OH}$ substitution have very strong antioxidant activities against peroxyl radicals (32).

Among the principal properties that may account for the potential health benefits of flavonoids is their antioxidant activity. Several in vitro studies have demonstrated that flavonoids can scavenge superoxide, hydroxyl and peroxyl radicals, affecting various steps in the arachidonate cascade via cyclooxygenase- 2 or lipoxygenase (32). In addition to these important effects, they have membrane-stabilizing properties and also affect some processes of intermediary metabolism and inhibit lipid peroxidation in different systems. Some of them have been shown to increase the mucosal content of prostaglandins and mucus in gastric mucosa, showing cytoprotective effects. Several of them prevent gastric mucosal lesions pro- duced by various experimental ulcer models and protect the gastric mucosa against different necrotic agent (32).

Several mechanisms may account for the antioxidant activity of flavonoids in addition to free radical scavenging, i.e., chelating of transition metal ions, inhibition of oxidant enzymes or production of free radicals by cells, and regeneration of $\alpha$-tocopherol from $\alpha$-tocopheroxyl radicals. They promote gastric mucosa formation, diminish acid mucosal secretion, inhibit the production of pepsinogen and decrease ulcerogenic lesions (33).

The active compounds of plants, flavonoids, triterpenes and tannins may be regarded as possible active compounds against gastric lesions by acting as protective factors or increasing antioxidant activity. Three distinct mechanisms of protection by flavonoids have been identified: the alteration of GSH metabolism, quenching of reactive oxygen species and the inhibition of $\mathrm{Ca}^{2+}$ influx that signals the last step in the cell death cascade induced by glutamate (34).

Among the rich unexploited world flora a large number of species have folkloric medicinal uses. Extracts from the plants $\mathrm{Mo}$ mordica charantia (9), Angelica archangelica (35), Carum carvi (35), Chelidonium majus (35), Iberis amara (35), Matricaria recutita (35), Melissa officinalis (35), Mentha piperita (35), Silybum marianum (35), Anthemis nobilis (36), Brassica oleracea (36), Matricaria chamomilla (36), Maytenus aquifolium (36), Symphytum officinalis (36), Sorocea blomplandii (36), Zolernia ilicifolia (36) and Glycyrrhiza glabra (37) are used for the treatment of gastric ulcers and produce a dose-dependent anti-ulcerogenic activity associated with a reduced acid output and increased mucin secretion, an increase in $\mathrm{PGE}_{2}$ release and a decrease in leukotrienes. The anti-ulcerogenic activity of the extracts of Rhizophora mangle L. indeed was due, at least in part, to the presence of tannins (38). 
The anti-ulcerogenic activity of the extracts was also confirmed histologically. The cytoprotective effect of the extracts could be partially due to their flavonoid content and to their reactive oxygen species scavenging property (38).

The lyophilized water extracts of the active principles of these medicinal plants are effective $\mathrm{H}^{+}$donors, reducing agents and $\mathrm{H}_{2} \mathrm{O}_{2}$ scavengers in vitro, showing that the bioactive components can act as primary and secondary antioxidants and scavenge free radicals (7).

The mature fruits of Momordica charantia L. (Cucurbitaceae) are used externally for the rapid healing of wounds and internally for the treatment of peptic ulcers in Turkish folk medicine (9).

The principal constituents of extracts of Brassica oleracea, originated in the Mediterranean, are glycosides, enzymes, vitamins A, B, C and compounds containing sulfhydryl groups (36); Anthemis nobilis contents are azulene, flavonoids and sesquiterpene lactones; Symphytum officinalis is rich in alkaloids, allantoin, and mucilage. Aqueous extracts of Matricaria chamomilla have also shown the presence of sesquiterpene lactones, azulene, terpenic carbonyls, coumarins, resins and flavonoids (apigenin, quercetin, luteolin and patuletine) (36).

The crude hydroalcoholic extract of Rosmarinus officinalis decreased the ulcerative lesion index produced by indomethacin, ethanol and reserpine in rats. The pharmacological mechanism has no relationship with nitric oxide or prostaglandins. The crude hydroalcoholic extract of $R$. officinalis has active substances that increase the content of mucosal nonprotein sulfhydryl groups and antioxidant compounds which can react with N-ethylmaleimide (36).

Glycyrrhiza glabra (Papilionaceae) originated in the Mediterranean and the Middle East and has been used medicinally since at least 500 BC. Traditional uses include the treatment of peptic ulcers, asthma, pharyngi- tis, malaria, abdominal pain, and infections. The primary active constituents of G. glabra are the triterpene glycoside glycyrrhizin, flavonoids (liquiritin and isoliquiritin), isoflavonoids (isoflavonol, kumatakenin, licoricone and glabrol), chalcones, coumarins (umbelliferone, herniarin), triterpenoids, and phytosterols (37). Isoflavans from G. glabra have proved to be effective in protecting mitochondrial function against oxidative stresses (37).

\section{Artemisia douglasiana Besser and its active principle}

In Argentina the aerial part of $A$. douglasiana Besser has been used in folk medicine as a cytoprotective agent against the development of gastric ulcers, external treatment of skin injury and dermal ulcers. A. douglasiana Besser is a hexaploid species, a hybrid between $A$. suksdorfi Piper and A. ludoviciana Nutt. It is found on the western slopes of the US Rockies and in northern Baja California. The first report of its occurrence in Argentina was in 1967, in San Juan and Mendoza provinces, probably after introduction of the plant from Chile. It is known by the common name of "matico".

Phytochemical studies have shown that A. douglasiana is a species with a great diversity in secondary metabolite composition. Its major constituents are: sesquiterpene lactones, essential oils (azulene and chamazulene), flavonoids (rutin), vitamin $\mathrm{B}_{6}$, ascorbic, palmitic, caffeic, glutamic, stearic, gallic and ferulic acids, sanlonine, lignans, betaine, coumarins and polyacetylenes (36).

The active principle of the plant is dehydroleucodine (DhL), a sesquiterpenoid lactone of the guiainolide type (Figure 2). $\mathrm{DhL}$ increases gastric glycoprotein synthesis (1), as confirmed by histological studies of the gastric and duodenal mucosa (10). The $A$. douglasiana extract and DhL prevent lesions of the gastric mucosa induced by ethanol and other necrotizing compounds 
(10) and the absolute ethanol-induced gastric injury (4).

Recently, the antioxidant properties of $A$. douglasiana have been examined as a potential mechanism for its beneficial action. Thus, the antioxidant properties of $A$. douglasiana extract and its active principle, $\mathrm{DhL}$, in vitro and their application to the biological oxidative stress system are currently being studied.

\section{Gastroprotective effects of Artemisia douglasiana Besser and DhL}

The extract of the air-dried aerial parts of A. douglasiana showed significant cytoprotective activity.

The aqueous extract of $A$. douglasiana and its active principle possess anti-ulcer properties against ethanol- and acid-induced gastric mucosal damage. These effects have been interpolated from the pharmacological action of the extract on prostaglandin synthesis in gastric epithelium. The extract increases prostaglandin concentration in the gastric mucosa and protects the mucosa from damage induced by necrotizing agents.

In 1990, Giordano et al. (3) studied the cytoprotective action of $A$. douglasiana against the gastric lesion produced by acute administration of ethanol. The degree of erosion corresponded to a factor of 4.5 (large erosions and ulcerative perforations) in ethanol-treated rats and to a factor of only 0.5 in rats treated with both $A$. douglasiana extract and $\mathrm{DhL}$ before ethanol administration (10).

DhL prevented the gastric damage produced by $0.6 \mathrm{~N} \mathrm{HCl}, 0.2 \mathrm{~N} \mathrm{NaOH}$ and $25 \%$ $\mathrm{NaCl}$. Light and transmission electron microscopic studies showed that $A$. douglasiana and $\mathrm{DhL}$ pretreatment prevents the gross hemorrhagic lesions produced by ethanol (3).

Giordano et al. (3) showed that the presence of an exocyclic methylene group conjugated to a $\gamma$-lactone appears to be a structural requirement needed for the biological activ- ity exhibited for these compounds. These investigators concluded that the presence of the $\alpha$-methylene- $\gamma$-lactone moiety is a requirement for the cytoprotective activity observed, and the presence of the $\beta$-substituted or unsubstituted cyclopentanone ring is not a structural requirement for cytoprotective activity, contrary to its requirement for antitumor, antimicrobial, and antifeedant properties (3).

In 1995, Piezzi et al. (2) showed that the stomachs of rats pretreated with DhL presented a reduction of lesions induced by acute oral ethanol administration (3). No hemorrhage or hyperemia was observed. The epithelium of the mucosa had a cobblestone appearance, similar to that of control rats and was covered with a fine layer of mucus on the surface. The increased vascular permeability precedes the development of grossly visible mucosal hemorrhagic erosion. The cited investigators suggested that vascular damage plays an important role in the development of gross hemorrhagic erosion (3). In the stomachs treated with DhL, filaments or gross deposits occur in the mucosa; they probably dilute noxious agents and provide a favorable environment for rapid epithelial reconstitution. This may be

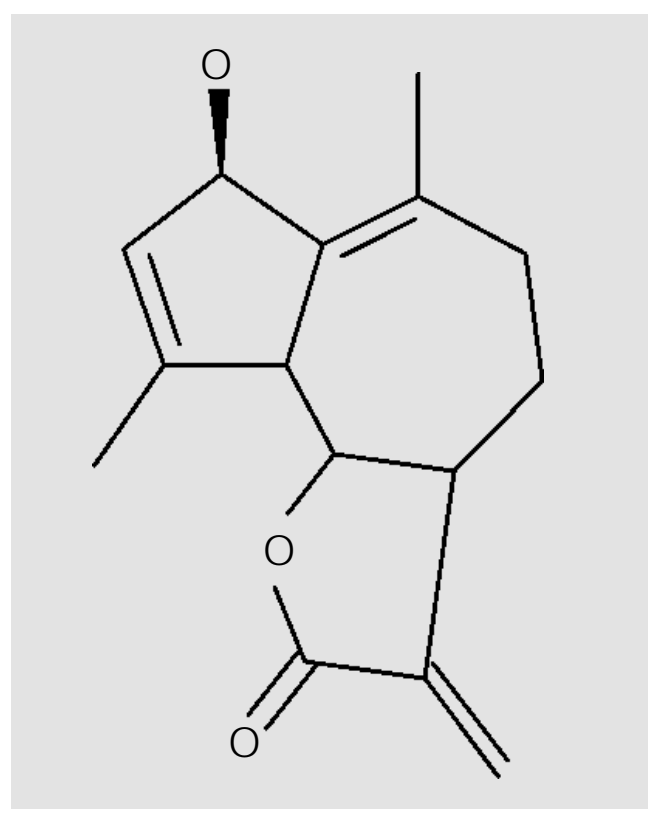

Figure 2. Structure of the dehydroleucodine, the active principle of Artemisia douglasiana Besser. 
one of the gastric defense mechanisms involved in the protection of the superficial mucosa.

Several different mechanisms could be proposed to explain the massive and accelerated mucus release induced by DhL. The protective action of DhL seems to be related to endogenous prostaglandin and to the ability of the drug to stimulate mucus production. The fact that the increase in the thickness after DhL treatment is similar in stomach $(83 \%)$ and duodenum (82\%) suggests that both tissues present a similar secretory response to the drug. The protective action of $\mathrm{DhL}$ on gastric mucosa is not related to an antisecretory property since it does not decrease acid secretion, but triggers the defense mechanisms of the mucosa.

Prostaglandins have been shown to increase the amounts of luminal mucus and the resistance of the gastrointestinal tract to injury in several experimental models. They are believed to exert their cytoprotective actions through the stimulation of mucus and bicarbonate secretion, the maintenance of mucosal blood flow, and by enhancing the resistance of epithelial cells to injury induced by cytotoxins.

In 1998, María et al. (39) found an increase in gastric prostaglandin $\mathrm{E}_{2}$ levels, measured by radioimmunoassay in subchronically DhL-treated rats. It is also possible that DhL may alter the activity of certain receptors in the gastroduodenal mucosa, such as serotonin and/or muscarinic receptors. The muscarinic receptors mediate the secretion of gastric acid, pepsinogen, and mucus in gastric mucosa by stimulating the phosphoinositide second messenger system. It is also possible that massive mucus secretion after treatment with $\mathrm{DhL}$ is mediated by the activation of certain histamine receptors, such as the $\mathrm{H}_{3}$ receptor, responsible for the increase in the amount of mucus in deep crypt cells of the fundic mucosa, by enhancing the synthesis of mucus. Interestingly, in 1999, Penissi and Piezzi (10) showed that
DhL by itself increases histamine levels in gastroduodenal tissue. Further studies are required to assess the significance of these observations.

\section{Antioxidant properties of Artemisia douglasiana Besser and DhL in vitro}

One of the mechanisms proposed for the activity of DhL is that this compound increases prostaglandin concentration in the gastric mucus and protects the mucosa from damage induced by necrotizing agents, and may suppress active oxidant species production $(10,39)$, involving sulfhydryl-containing compounds of the mucosa (3).

The antioxidant activity of $A$. douglasiana Besser (40) was evaluated by measuring the total reactive antioxidant potential (TRAP) and the total antioxidant reactivity (TAR) in vitro. The antioxidant activity of DhL was measured by chemiluminescence, evaluating the concentration necessary to decrease the initial luminescence by $50 \%$ $\left(\mathrm{IC}_{50}\right)$.

TRAP and TAR were measured by luminol-enhanced chemiluminescence (41). The reaction medium consisted of $100 \mathrm{mM}$ sodium phosphate buffer, $\mathrm{pH}$ 7.4, $20 \mathrm{mM}$ 2,2'azo-bis-2-amidinopropane, $0.04 \mathrm{mM}$ luminol and increasing volumes of plant extract $(10 \% \mathrm{w} / \mathrm{v})$ or DhL. Incubation of the mixture at room temperature generated a nearly constant light intensity that was measured directly with a Packard Tri-Carb scintillation counter.

The addition of the antioxidant plant extract or DhL decreased chemiluminescence to basal levels for a period (induction time) proportional to the concentration of antioxidant until luminol radicals were regenerated. The system was calibrated using the vitamin E analogue Trolox $(0.150 \mathrm{mM})$. A comparison of the induction time after the addition of known concentrations of Trolox and plant extract permitted the determination of TRAP values as equivalents of the Trolox concen- 
tration necessary to suppress the emitted luminescence to be obtained. The TAR index was calculated from the instantaneous decrease in luminescence associated with incorporation of the extract into a reaction medium consisting of $2 \mathrm{mM}$ ABAP and 10 $\mathrm{nM}$ luminol in $0.1 \mathrm{M}$ borate buffer, $\mathrm{pH}$ 10.2. The system was calibrated with $150 \mathrm{nM}$ Trolox and the chemiluminescence was measured with a luminometer (Labsystem Luminoskan L model, Helsinki, Finland). The concentration necessary to decrease the initial luminescence by $50 \%\left(\mathrm{IC}_{50}\right)$ was evaluated by plots of $\mathrm{I}^{\mathrm{o}} / \mathrm{I}$ against concentration, where $\mathrm{I}^{\mathrm{o}}$ and $\mathrm{I}$ are the luminescence intensity before and after the incorporation of the scavenger (40).

The TRAP value for the $A$. douglasiana extracts obtained by quenching luminol-enhanced chemiluminescence was $95.4 \pm 0.9$ $\mu \mathrm{M}$ Trolox. The TAR value for the extract was $30.7 \pm 0.4 \mu \mathrm{M}$ Trolox. Moreover, the $\mathrm{IC}_{50}$ for DhL was $116.2 \pm 0.4$ and the $\mathrm{IC}_{50}$ for the $A$. douglasiana extract was $14.8 \pm 0.2$ $\mu \mathrm{g} / \mathrm{ml}$. The difference in the mean values for the two groups was greater than would be expected by chance; there was a statistically significant difference between the input groups (Student $t$-test; $\mathrm{P}<0.001$ ) (40).

The results indicate that, as described for the antioxidant capacity of blood plasma (40), the TRAP value was considerably higher than the TAR value. This may be due to the presence of antioxidants of relatively low reactivity. These findings are similar to the results obtained with different extracts of several medicinal plants (42). The chemiluminescence decay following the addition of the plant extract was qualitatively different from that obtained with Trolox (40). These differences could be the result of the presence of efficient and inefficient antioxidants in the extract. The concentration of efficient antioxidants in Trolox equivalents can be calculated from the fast decay extent, while the change in luminol chemiluminescence measured after a long time can be related to the total amount of antioxidants (efficient and inefficient) present in the sample. The measured induction times and $\mathrm{I}^{\circ} / \mathrm{I}$ were proportional to the concentration of the extract for both DhL and Trolox (40). The extract showed a faster decay than DhL.

The data reported by María et al. (40) indicate that the extract of $A$. douglasiana and $\mathrm{DhL}$ have an antioxidant capacity, which is more pronounced in the extract. This difference may be the result of the presence of several antioxidants in the plant extract such as flavonoids that may be responsible for the antioxidant capacity, with possible additional protection against oxidative stress. Since the substitution of the molecule nucleus with hydroxyl groups is essential to acquire significant antioxidant activity, DhL probably is not an efficient antioxidant compound in vivo.

The relationship between prostaglandins and leukotrienes, the arachidonic acid products of prostaglandin $\mathrm{H}$ synthase (PGHS) and 5-lipoxygenase, respectively, seems to be an important factor in gastric ulcers. Many phenolic compounds, including catecholamines, have been shown to modulate the PGHS and 5-lipoxygenase pathways of arachidonic acid (32).

Phenols have a dual effect on prostaglandin biosynthesis, with low concentrations stimulating and high concentrations inhibiting PGHS. Phenols stimulate prostaglandin synthesis by acting as reducing substrates for the oxidized intermediates of PGHS, thereby accelerating the peroxidase cycle and by functioning as electron-donating cosubstrates for the peroxidase component of PGHS. Phenols inhibit the cyclooxygenase2 activity of PGHS by competing for the arachidonic acid-binding site and by competitive reduction of PGHS. The modulation of hydroperoxide tone by phenols is probably the key element explaining the suppression of arachidonic acid metabolism by PGHS. The stimulatory effect of phenols on $\mathrm{PGE}_{2}$ formation may be based on their ac- 
tion as co-substrates for the peroxidase reaction (32).

The extract of $A$. douglasiana and its active principle $\mathrm{DhL}$ significantly prevent the formation of gastric lesions induced by various necrotizing agents $(28,40)$, and this activity could be due, in part, to their capacity for scavenging oxygen free radicals which may be involved in peptic ulcer development. A. douglasiana exhibits a varied system of primary and secondary metabolites that protect cells from changes driven by pro-oxidants. Other important components present in the A. douglasiana extracts are coumarins (benzopyrones). They are effective against oxidative stress by acting in a similar manner to flavonoids, i.e., inhibiting lipoxygenase and cyclooxygenase- 2 pathways, inhibiting production of $\mathrm{O}_{2}{ }^{--}$by neutrophils, scavenging $\mathrm{OH}^{\bullet}$ and $\mathrm{O}_{2}{ }^{--}$radical, inhibiting the activity of hypochlorous acid, and chelating iron ions (43).

The gastroprotective effect of $A$. douglasiana extracts and $\mathrm{DhL}$ on gastric mucosal injury may be mediated by local release of sensory neuropeptides, nitric oxide, and prostaglandin. Inhibition of lipid peroxidation and cyclooxygenase- 2 is considered to be an important target for the chemoprevention of gastrointestinal ulcers. Further studies are needed to determine if $A$. douglasiana and $\mathrm{DhL}$ regulate the responses of the gastric mucosa to stress through mechanisms that include heat shock proteins, prostanoids and nitric oxide besides their antioxidant properties.

A. douglasiana and DhL have been shown to have antioxidant properties in a tube experiment, to protect the gastric mucosa from experimental ulcerations in vivo, and to accelerate the healing of gastric ulcers in hu- mans. These results suggest that $A$. douglasiana and $\mathrm{DhL}$ may partly protect the gastric mucosa from acute injury and may promote the healing of chronic gastric ulcers by their antioxidant activity.

\section{Conclusions and future directions}

The extract of $A$. douglasiana Besser possesses significant free radical scavenging and antioxidant activity in vitro, but $\mathrm{DhL}$ proved to be less efficient as an antioxidant than the plant (40). The therapeutic action of the extract of $A$. douglasiana Besser and $\mathrm{DhL}$ could be due, in part, to their ability to scavenge oxygen free radicals, which may be involved in ulcer and inflammatory diseases. Indeed, the main mechanism involved in the cytoprotective action of the compound is mucus secretion. DhL increases in the thickness of the adherent mucus gel layer (10). These natural compounds are thought to possess significant gastrointestinal cytoprotective activity.

A. douglasiana Besser and DhL may represent an attractive therapeutic option for gastric ulcers and inflammation, both as cytoprotective agents and as antioxidants for a wide range of clinical applications. We are currently evaluating the antioxidant activity of the A. douglasiana Besser extracts and DhL in an acute experimental model of ethanolinduced oxidative stress in the rat stomach.

\section{Acknowledgments}

We are grateful to Drs. Alejandra María, Oscar Giordano and Jorge Guzmán, Universidad Nacional de San Luis, San Luis, Argentina, for their contribution. 


\section{References}

1. Guardia T, Guzmán J, Pestchanker M, Guerreiro E \& Giordano O (1994). Mucus synthesis and sulfhydryl groups in cytoprotection mediated by dehydroleucodine, sesquiterpene lactones. J ournal of Natural Products, 57: 507-509.

2. Piezzi R, Guzmán J , Guardia T, Pestchanker M, Guerreiro E \& Giordano O (1995). Dehydroleucodine prevents ethanol-induced necrosis in the mouse duodenal mucosa. A histological study. Biocell, 19: (Suppl 1): 27-33.

3. Giordano O, Guerreiro E, Pestchanker M, Guzmán J , Pastor D \& Guardia T (1990). The gastric cytoprotective effect of several sesquiterpene lactones. J ournal of Natural Products, 53: 803-809.

4. Giordano O, Pestchanker M, Guerreiro E, Guzmán J , Pastor D \& Guardia T (1992). Structure activity relationship in the gastric cytoprotective effect of several sesquiterpene lactones. J ournal of Medicinal Chemistry, 35: 2452-2458.

5. Hahn K, Park I, Kim Y, Kim J, Cho S, Lee S \& Young J (1997). Role of rebamipide on induction of heat-shock proteins and protection against reactive oxygen metabolite-mediated cell damage in cultured gastric mucosal cells. Free Radical Biology and Medicine, 22 (Suppl 4): 711-716.

6. Lutnicki K, Szpringer E, Czemy K \& Ledwozyw A (2001). Effects of ethanol and arachidonic acid pathway inhibitors on the effectiveness of gastric mucosa cytoprotection. Folia Morphologica, 60 (Suppl 1): 47-56.

7. Czinner E, Hagymasi K, Blazovics A, Kery A, Szoke E \& Lemberkovics E (2001). The in vitro effect of Helichysi flos on microsomal lipid peroxidation. J ournal of Ethnopharmacology, 77: 31-35.

8. KannerJ \& LapidotT (2001). The stomach as a bioreactor: dietary lipid peroxidation in the gastric fluid and the effects of plantderived antioxidants. Free Radical Biology and Medicine, 31 (Suppl 11): 1388-1395.

9. Gurbuz I, Akyuz C, Yesilada E \& Sener B (2000). Anti-ulcerogenic effect of M omordica charantia $L$. fruits on various ulcer models in rats. J oumal of Ethnopharmacology, 71: 77-82.

10. Penissi A \& Piezzi R (1999). Effect of dehydroleucodine on mucus production. A quantitative study. Digestive Diseases and Sciences, 44 (Suppl 4): 708-712.

11. Cross C, Halliwell B \& Allen A (1984). Antioxidant protection: a function of tracheobronchial and gastrointestinal mucus. Lancet, 1: 1328-1330.
12. Seno K, J oh T, Yokoyama $Y \&$ Itoh $M$ (1995). Role of mucus in gatric mucosal injury induced by local ischemia/reperfusion. J ournal of Laboratory and Clinical Medicine, 126 (Suppl 13): 287-293.

13. Mogy M, Kitajima M, Kiuchi T, Kawakami H \& Hirano H (1990). Alteration of the gastric mucosal glycoprotein in stress. Nippon Shokakibyo Gakkai Zasshi, 87 (Suppl 5): 1131-1138.

14. Tsukimi $Y \&$ Okabe S (2001). Recent advances in gastrointestinal pathophysiology: role of heat shock proteins in mucosal defense and ulcer healing. Biological and Pharmaceutical Bulletin, 24 (Suppl 1): 1-9.

15. Rotukan K (1999). Molecular stress response in the stomach. Nippon Yakurigaku Zasshi, 114 (Suppl 59): 265-272.

16. Vorobjova $\mathrm{T}$, Ananieva $\mathrm{O}, \mathrm{Maaroos} \mathrm{H}$, Sipponen P, Villako K, Utt M, Nilsson I, Wadstrom T \& Uibo R (2001). Seropositivity to Helicobacter pylori heat shock protein 60 is strongly associated with intensity of chronic inflammation, particularly in antrum mucosa: an extension of an 18year follow-up study of chronic gastritis in Saaremaa, Estonia. FEMS Immunology and Medical Microbiology, 30 (Suppl 2): 143-149.

17. Rotukan K (2000). Role of heat shock proteins in gastric mucosal protection. J ournal of Gastroenterology and Hepatology, 15 (Suppl D): 12-19.

18. Saika M, Ueyama T \& Senba E (2000). Expression of immediate early genes, HSP70, and COX-2 mRNAs in rat stomach following ethanol ingestion. Digestive Diseases and Sciences, 45 (Suppl 12): 2455-2462.

19. Kay H, Grindle K \& Magness R (2000). Ethanol exposure induces oxidative stress and impairs nitric oxide availability in the human placental villi: a possible mechanism of toxicity. American J ournal of Obstetrics and Gynecology, 182 (Suppl 3): 682-688.

20. Kato S, Tanaka A, Kunikata T, Mizoguchi H $\&$ Takeuchi K (2000). The roles of nitric oxide and prostaglandins in alterations of ulcerogenic and healing responses in adjuvant-induced arthritic rat stomachs. Alimentary Pharmacology and Therapeutics, 14 (Suppl 1): 18-25.

21. Yoshikawa T, Ueda S, Naito $Y$, Oyamada H, Morita Y, Yoneta T \& Kondo M (1989). Role of oxygen-derived free radicals in gastric mucosal injury induced by ischemia or ischemia reperfusion in rats. Free
Radical Research Communications, 7: 285-291.

22. Bagchi D, Carryl O, Tran M, Krohn R, Bagchi DJ , Garg A, Bagchi M, Mitra S \& Stohs $S$ (1998). Stress, diet and alcoholinduced oxidative gastrointestinal mucosal injury in rats and protection by bismuth subsalicylate. J ournal of Applied Toxicology, 18 (Suppl 1): 3-13.

23. Gonzalez F, Portela T, Stipp E \& Di Stasi L (2001). Antiulcerogenic and analgesic effects of Maytenus aquifolium, Sorocea blomplandii and Zolernia ilicifolia. J ournal of Ethnopharmacology, 77: 41-47.

24. Hirokawa M, Miura S, Yoshida H, Kurose I, Shigematsu T, Hokari R, Higuchi $H$, Watanabe N, Yokoyama Y, Kimura H, Kato S \& Ishii H (1998). Oxidative stress and mitochondrial damage precedes gastric mucosal cell death induced by ethanol administration. Alcoholism, Clinical and Experimental Research, 22 (Suppl 3): 111S-114S.

25. Terano A, Hiraishi H, Ota S, Shiga J \& Sugimoto T (1989). Role of superoxide and hydroxyl radicals in rat gastric mucosal injury induced by ethanol. Gastroenterologia J aponica, 24: 488-493.

26. Hemandez Muñoz R, Montiel Ruiz $C \&$ Vazquez Martinez O (2000). Gastric mucosal cell proliferation in ethanol-induced chronic mucosal injury is related to oxidative stress and lipid peroxidation in rats. Laboratory Investigation, 80 (Suppl 8): 1161-1169.

27. Marazzi-Uberti E \& Turba C (1961). Pharmacological study of 2-p (propionyl-omethoxy-phenoxy)-1,2-propaneidiol. J ournal of Natural Products, 53: 803-809.

28. Piezzi R, Guzmán J, Guardia T, Pestchanker M, Guerreiro E \& Giordano O (1992). Dehydroleucodine prevents ethanol-induced necrosis in the rat gastric mucosa. A histological study. Microscopía Electrónica y Biología Celular, 16 (Suppl 1): 45-56.

29. Marotta F, Tajiri $H$, Safran $P$, Fesce E \& Ideo $G$ (1999). Ethanol related gastric mucosal damage: evidence of a free radicalmediated mechanism and beneficial effect of oral supplementation with bionormalizer, a novel natural antioxidant. Digestion, 60 (Suppl 6): 538-543.

30. Araki $H$, Ukawa $H$, Sugawa $Y$, Yagi $K \&$ Takeuchi K (2000). The roles of prostaglandin $\mathrm{E}$ receptor subtypes in the cytoprotective action of prostglandin $E_{2}$ in rat stomach. Alimentary Pharmacology and Therapeutics, 14 (Suppl 1): 116-124. 
31. Nakatami N (2000). Phenolic antioxidants from herbs and spices. Biofactors, 13 (Suppl 1-4): 141-146.

32. Alanko J, Riutta A, Holm P, Mucha I, Vapatalo H \& Metsa-Ketela T (1999). Modulation of arachidonic acid metabolism by phenols: relation to their structure and antioxidant/prooxidant properties. Free Radical Biology and Medicine, 26 (Suppl 1-2): 193-201.

33. La Casa C, Villegas I, Alarcón de la Lastra C, Motilva V \& Martín Calero M (2000). Evidence for protective and antioxidant properties of rutin, a natural flavone, against ethanol induced gastric lesions. J ournal of Ethnopharmacology, 71: 45-53.

34. Ishige K, Schubert D \& Sagara Y (2001). Flavonoids protect neuronal cells from oxidative stress by three distinct mechanisms. Free Radical Biology and Medicine, 30 (Suppl 4): 433-466.

35. Khayyal M, el-Ghazaly M, Kenawy S, Seifel-Nasr M, Mahran L, Kafafi Y \& Okpanyi S (2001). Antiulcerogenic effect of some gastrointestinally acting plant extracts and their combination. Arzneimittel-Forschung, 51 (Suppl 7): 545-553.

36. Alonso J (1998). Tratado de Fitomedicina. In: Alonso J (Editor), Bases Clínicas y Farmacológicas. ISIS Editora, Buenos Aires, Argentina, 198, 422, 424, 690, 693, 735.

37. Haraguchi $\mathrm{H}$, Yoshida $\mathrm{N}$, Ishikawa $\mathrm{H}$, Tamura Y, M izutani K \& Kinoshita T (2000). Protection of mitochondrial functions against oxidative stresses by isoflavans from Glycyrrhiza glabra. J ournal of Ethnopharmacology, 52 (Suppl 2): 219-223.

38. Sánchez Perera L, Ruedas D \& Gomez B (2001). Gastric antiulcer effect of Rhizophora mangle L. J ournal of Ethnopharmacology, 77: 1-3.

39. María A, Franchi A \& Wendel G (1998). Gastric cytoprotective activity of dehydroleucodine in rats. Role of prostaglandins. Biological and Pharmaceutical Bulletin, 21 (Suppl 4): 335-338.

40. María A, Repetto M, Llesuy S, Giordano O, Guzmán J \& Guerreiro E (2000). Anti- oxidant activity of Artemisia douglasiana Besser extract and dehydroleucodine. Phytotherapy Research, 14: 558-560.

41. Lissi E, Salin-Hanna M, Pascual C \& Del Castillo M (1995). Evaluation of total antioxidant potential (TRAP) and total antioxidant reactivity from luminol enhanced chemiluminescence measurements. Free Radical Biology and Medicine, 18: 153158.

42. Desmachelier C, Repetto M, Coussio J, Llesuy S \& Ciccia G (1997). Total reactive antioxidant potential (TRAP) and total antioxidant reactivity (TAR) of medicinal plants used in Southwest Amazonia (Bolivia and Peru). International J ournal of Pharmacognosy, 35 (Suppl 4): 1-9.

43. Greenspan H \& Aruoma O (1994). Oxidative stress and apoptosis in HIV infection: a role for plant-derived metabolites with synergistic antioxidant activity. Immunology Today, 15 (Suppl 5): 209-213. 